\title{
Inclusion of Students with Autism from Integration Aides' Perspective: Characteristics and Challenges
}

\author{
Tamar Groman \\ Ono Academic College, Kiriat Ono, Israel \\ Email: tammy.groman@gmail.com
}

How to cite this paper: Groman, T. (2022) Inclusion of Students with Autism from Integration Aides' Perspective: Characteristics and Challenges. Open Access Library Journal, 9: e8419.

https://doi.org/10.4236/oalib.1108419

Received: February 3, 2022

Accepted: February 21, 2022

Published: February 24, 2022

Copyright $\odot 2022$ by author(s) and Open Access Library Inc.

This work is licensed under the Creative Commons Attribution International License (CC BY 4.0).

http://creativecommons.org/licenses/by/4.0/

(c) (i) Open Access

\begin{abstract}
Integrating students with high-functioning autism is a complicated process, influenced by various factors, among them, the integration aides' perceptions and feelings about the process itself and the relationship with the student. The professional literature indicates necessary conditions for an effective integration process such as: availability of professional employees to assist teachers in implementing integration, counseling and training, built-in time frames for multi-professional meeting, creating intervention programs and adjusting the educational environment to special needs (Simpson, Boer-Ott, \& SmithMyles, 2003). This study examines the experience of integrating students diagnosed with high-functioning autism, from the point of view of five integration aides in primary school. The study was carried out in the center of Israel and is based on a qualitative methodology. The interviews show that despite significant challenges, internal and autonomous motivational characteristics, such as dedication to work, diligence, perseverance, job satisfaction as well as an opportunity for growth; personal and professional development were expressed in the interviews.
\end{abstract}

\section{Subject Areas}

Educational Psychology, Educational Technology

\section{Keywords}

High Functioning Autism, Inclusion, Integration Aides

\section{Autism}

Autism is a broad neurodevelopmental disorder that appears at a young age 
and persists throughout life, characterised by two specific areas of impairment: communication and difficulties in establishing a mutual connection, and repetitive behavior patterns (Law \& McPartland, 2016) [1]. By the time the fifth edition of DSM was released, in May 2013, autism had been defined as an independent diagnosis with different syndromes such as Asperger and NOS-PDD syndromes.

The criteria for diagnosis according to DSM-5 include several fundamental changes: consolidating all five deficiencies into one diagnostic sequence under one general name ASD-Autistic Spectrum Disorder, with each diagnosis having three degrees of severity, which are determined by the extent of the need for support for functioning and adaptation. In the two main areas (unlike the previous definition, which also included reference to communication and language disabilities), difficulties were observed in children with ASDs: difficulties in social communication and mutual interaction and limited and repetitive behavior patterns, alongside with different sensory modulation (Al-Qasheh, 2017) [2].

The functioning's characteristics of people diagnosed with autism may be expressed by difficulties in the ability to form mutual social relationships, understand social situations, and the ability to conduct themselves in accordance with the accepted patterns of social and emotional communication. People with autism find it difficult, among other abilities, to understand the importance of eye contact and facial expressions as part of social interactions and to develop relationships that have mutual emotional communication. Sometimes this is accompanied by difficulty in verbal communication as well. There is also a strong tendency towards limited interest or rigid adherence to rituals, behaviors, and regular habits (Law \& McPartland, 2016) [1].

\subsection{High-Functioning Autism}

The term high-functioning autism (HFA) describes normal cognitive function in terms of thinking and language skills, averaged IQ level and above, along with characteristics found in the clinical definition. Usually, people with HFA use language for communication and independent in daily activities.

The clinical and behavioral traits that characterise high-functioning autism are related to the quality of social interaction; difficulties in developing friendships, using of nonverbal behavior, tendency to ignore or interpret in an uninformed way such as gaze, facial gestures, body language and vocal intonation (Hiraiwa, 2012) [3]; difficulties in understanding social situations and understanding the intentions of others; difficulties in the quality of delicate communication abilities (difficulties in communicating conversation, unique speech patterns in terms of pitch, intonation, use of official and pedantic language, and little or misuse in figurative expressions and slang) along with having unusual areas of interest in terms of their content and intensity and preference for routines (Levinger, 2010) [4]. 


\subsection{Integration Aides' Role}

Bauminger, Lake-Ben-Artzi, \& Kimchi (2007) [5] examined the processes required for effective integration of students with autism in educational frameworks. The researchers emphasise the need to adapt the educational environment to the students' needs, using unique teaching strategies and providing adjustments. In the social sphere, since the difficulties of these students are multidimensional, alongside disruptions in the spontaneous social learning ability, it is necessary to choose strategies and mediation programs, which rely on their high cognitive abilities.

In order to promote beneficent processes, structured intervention is required, tailored to the students' needs. Without this intervention, these students may be at risk of feeling lonely and socially distressed. The common basis of all strategies in both areas is the use of cognitive-behavioral therapy strategies. The use of cognitive processes for social learning requires systemic mediation processes (Bauminger, Lake-Ben-Artzi, \& Kimchi, 2007) [5].

Brookdale Institute's studies show that assistive services were particularly important for the integration of students with special needs. Most parents reported receiving an aide to their child on behalf of the local authority (Milstein and Rivkin, 2013 [6]; Neon, Milstein and Marom, 2011 [7]).

According to Giangreco, Halvorsen, Doyle, \& Broer (2004) [8] in order to create a solid foundation for effectively implementing the role of integration aides' in schools, providing students with high functioning autism the best educational tools, schools are required to address three components: 1) Engaging in the support required to streamline and clarify the integration aid's role (clarification of the role, manner of employment, training and supervision); 2) Creating an informed decision-making process about the need for assistive support; 3) Creating alternatives, relating to a variety of activities that supervisors and school administrators can encourage, including the involvement of parents, students (with disabilities and without disabilities) teachers and assistants, so that the excess use of aid support is reduced.

The professional literature indicates necessary conditions for an effective integration process such as: availability of professional employees to assist teachers in implementing integration, counseling and training, built-in time frames for multi-professional meeting, creating intervention programs and adjusting the educational environment to special needs (Simpson, Boer-Ott, \& Smith-Myles, 2003) [9].

Although the aide's role is seen as one of the most important components in the integration process (Neon, Milstein and Marom, 2011 [7], Milstein and Rivkin, 2013 [6]), there seems to be a disregard for academic research regarding the integration aides' feelings and perceptions of the process. This study will examine the role of integrating high-functioning autism students in primary school, from the perspective of the aides. The current research was carried out using a qualitative methodology by analysing structured interviews with five integration 
aides in primary school.

\section{Methodology}

The current research examines the experience of integrating students with high-functioning autism, in primary school, from the perspective of five integration aides. The selected research method is qualitative research in light of the epistic and ethical position of qualitative research, on the interpretive nature of qualitative research. The qualitative research does not seek to reveal an "objective" truth, but rather to investigate, examine and expose the different interpretations and meanings that people attribute to the reality and structures in which they operate (Xen, Kramer Nevo, 2010) [10].

\subsection{Participants}

Five integration aides were interviewed in the current research.

Characterisations of their seniority in the education field, educational training and previous experience are shown in Table 1.

\subsection{The Interview}

Data collection was gathered through a structured interview including sixteen questions, which enabled the interviewees to provide subjective meanings to their behavior, feelings, beliefs, attitudes, and views in relation to their role in the integration process, for example: "What are the main challenges involved in the integration process?" "What factors (strategies/traits etc.) make coping with those challenges more effectively?" "How would you describe the relationship between you and the student?" "How would you describe the level of your involvement in the teamwork? Do you think it should be increased? If so, in what ways?" "How would you describe the professional team's attitude towards you?" "With whom do you consult for guidance and assistance in dealing with challenges in the process?" "How this role affects you professionally and personally?"

Table 1. Interviewees' educational and experience stage.

\begin{tabular}{cccccc}
\hline $\begin{array}{c}\text { Integration } \\
\text { aide (Initial) }\end{array}$ & Age & Education & Seniority & $\begin{array}{c}\text { Formal special education } \\
\text { training }\end{array}$ & $\begin{array}{c}\text { Previous experience } \\
\text { in educational role }\end{array}$ \\
\hline D & 28 & Psychology (B.A) & 2 & $\begin{array}{c}\text { Applied behaviour analysis } \\
\text { (ABA) program }\end{array}$ & $\begin{array}{c}\text { Previous work experience } \\
\text { with students with autism }\end{array}$ \\
$\mathrm{A}$ & 37 & Art Studies & 5 & $\begin{array}{c}\text { Applied behaviour analysis } \\
\text { (ABA) program }\end{array}$ & No previous experience \\
$\mathrm{G}$ & 38 & $\begin{array}{c}\text { Industrial Engineering } 8 \\
\text { Management (B.Sc) }\end{array}$ & 7 & Special education courses & No previous experience \\
$\mathrm{J}$ & 45 & 12 school years & 12 & Special education courses & No previous experience \\
$\mathrm{H}$ & 33 & 12 school years & 4 & Special education courses & No previous experience \\
\hline
\end{tabular}




\subsection{Data Analysis}

This study was analysed according to the principles of the analysis of qualitative research (Shakedy, 2003) [11]. In the initial reading phase, all the answers were read several times for a complete impression when, during reading, notes and thoughts were written for the analysis. Through this process, the findings were gathered into two main categories: One is the role of the aide that combines challenges and dilemmas in intrapersonal aspects; The second is the role of the aide that involved intrapersonal and interpersonal qualities. Through this division, a distinction was made between the difficulties and forces in the aide's role, both at the intrapersonal and interpersonal levels. Each of the two categories consists of several content subcategories, which will be presented in the findings section.

\section{Findings}

From the interviews that were carried in the current research several interpersonal and intrapersonal challenges and dilemmas have been revealed:

\subsection{The Nature and Quality of the Relationship between the Aide and the Student-between Rejection-Proximity and Dependence-Autonomy}

The relationship with the student has been emphasised in all interviews pointing on two main dilemmas: 1) along with the desire of the aides to protect the students from disappointments or failures, they expressed concerns about allowing them to experience different situations and the need to adopt a pattern of "overprotection" behavior; 2) the level of closeness between the aide and the student which raises contrast feelings such as rejection and distance, belonging, boundaries, and adjusting the relationship to the specific context in which the student operates. "I find the relationship between me and the child as warm. We love each other very much, but sometimes it is also very difficult for us with each other. The child knows that I care for him, and many times does not allow me to speak to another child. The child sometimes creates distance, wishing to be like other children without of assistance in the class" (G). "The boy won't let me get close to him; I feel rejected. I need to try to get close...He doesn't say good morning to me. I can't give up. I feel rejected, but that's the job". "I'm trying to disguise myself as an aide" (J). "Our relationship is good. I feel like more authoritarianism is needed on my side. I ask myself how I express myself in the class. Which level is the distance I need to keep, that the kids won't feel like I'm just with him, that I'm there because of him, and for him. When and how to help, specifically for each situation. When to let go, when to hold on a little longer. When to bring him to act within a social situation, in interaction with the other children" (D).

\subsection{Collaborations with the Staff and Their Professional Place in the Educational Team}

This aspect raises the question of how much the educational staff perceives the 
aide as a figure with professional knowledge relevant to consultation processes. In all interviews the reference to the question "How do you see the attitude of the staff towards you?" is extremely positive, describing situations of an optimal cooperation. Dilemmas arise such as: a lack of understanding and knowledge of the staff in the integration process, the aide as a threatening factor that sees firsthand the functioning of the teacher, the exclusion of the aide, a disregard for the professional place of the aide.

In my opinion, the aides must be involved in any decision in the integration process. Being a part of the WhatsApp group...They need to be part of the school's broader staff, get emails like everyone else, to get involved and know what's going on.

There is a perception of aides, who are in a lower place. The staff are sometimes condescending. There must be a mutual respect between class teachers and the aides even if it is not always convenient for them (G).

\subsection{The Need for Training and Guidance}

All the interviewees expressed clearly and decisively the need for both ongoing training and the expansion of the professional toolbox through a concentrated course. The guidance meets two needs: at the visible level, purchasing knowledge to best fulfill their function; at the hidden level, receiving guidance allows the aide to feel belong and meaningful in the process.

"Sometimes I need counseling. This is where I have. I can consult with the therapists and the educators. They're always helping me" (J). I would love to take a course on integration and Inclusion, to enrich my knowledge. I would love to receive more information and guidance about autism (G). "Any additional training and/or information will only improve the process. Not in all situations the integrator or teacher knows how to handle well. A lot is done by intuition and familiarity with the child. Sometimes I feel like I'm missing real tools for work. First, I consult with the educator and together we try to find a solution. Usually, I receive a response although not always in-depth" $(\mathrm{H})$. The training allows the aide to feel as an integral part of the educational staff and to his/her professional role.

\subsection{The Terms of the Employment and the Professional Status}

One of the crucial dilemmas that has been expressed in the interviews is related to the way in which the role is perceived as well as the question of the employment's terms and wages. "This profession is not so outwardly valued; There is a perception of aides, who are in a lower place" $(\mathrm{H})$. The aides expressed the feeling that there is no recognition yet from both the broad system (the Ministry of Education) and the school system in assisting as a part of the educational staff. A lack of recognition is reflected in the conditions of their employment, in regulating their status, in their role in the educational system, and in providing training. 


\subsection{Personal Characteristics}

Several motivational characterisations have been mentioned repeatedly as those that constitute the driving force in the aides' role performing it in the best possible way-caring, dedication to work, diligence, and perseverance.

"Being Patient, proactive, responsible, motivational, excellent in teamwork (that) I care very much, in every role I perform. I am a very dedicated person. Even after hours of operation. Not giving up. Optimistic. Wants and believes he will succeed" (D). Alongside motivational elements, it is possible to see a few strengths related to the field of positive emotions such as: optimism (the belief that the future will be positive), love (the ability to be loved and give love), and a feeling of satisfaction at work.

“Those qualities I feel that influence the integration process's success are: love of children's inner world, ability to conspire with the children in the class, patience, perseverance, optimism, faith in the process" (G).... "Don't give up. Optimistic. Wants and believes that he will succeed" (D) "Patience, calmness, understanding, flexible thinking, perseverance, humor, diligence" $(\mathrm{H})$ "I feel that the role contributes in a great way to me. It's one of the most significant roles in my life. I learn about myself, about society. The work challenges me in each day" (A). "I come home with a great satisfaction. I've helped those who need me" (J).

\subsection{Interpersonal Skills}

All the interviewees indicated that they have high level of interpersonal skills and that those skills are highly significant in the process. "High ability to work on all fronts cooperatively with the teachers, parents, classmates, and support teams. Communication with the system, teachers, counselor. I was most helpful in talking to people, to inform people, to say expectations, to communicate with the environment" (A). "In order to succeed in the role, there must be teamwork with the educator and the entire professional team" (D). All the interviewees noted several interpersonal skills such as: containment and empathy as significant contributors to the integration process's success.

\section{Discussion}

Integrating students with high functioning autism in the classroom is a complicated process accompanied by a professional team: educator/teachers, integrating aides, professional teachers, therapists, and instructors. In this study, the aides emphasised the need for collaborations and the construction of optimal communication as an important factor influencing the quality of the integration.

In a document written in ALUT (The Israeli National Autism Association) it has been mentioned that: "A quality integration process is constructed through a relaxed collaboration and trust relationship between the teacher and the aide and it is important to build an efficient and reciprocal communication between them, including building professional relationships with the team, based on trust and mutual respect, while creating cooperation." 
Concerning the quality of the relationship between the aide and the student, two main dynamics were outnumbered in the study: the continuum between rejection and proximity and the continuum between dependence and independence. The issue of dependence/independence is one of the main concerns in both academic field and policymakers. Thus, in ministry of education document, from January 2014, a specific reference appears concerning this issue: "The position of the professionals in the Ministry of Education, based on studies from Israel and abroad, is that the role of the aide, in those cases in which it was decided to assign an aide to a student with autism, to help the student participate in the curriculum and understand the learning materials and the tasks provided in the lesson. In this way, the educator and class teachers will be able to work with all students" (Abramson, Golub, Kassirer, Irad, \& Berger, 2017) [12]. The professional literature dealing with this issue raises the concern of improper use, or an excess of closeness between the aide and the student (Giangreco, 2013) [13].

According to Seligman (2005) [14] there are several strengths that predict happiness: optimism, love, gratitude, enthusiasm. In this study, all aides used the word satisfaction when they were asked to describe their role, as well as noting traits that help them perform their duties, which are associated with feelings of happiness.

Ben-Shahar (2010) [15] presents several concepts of role's elements, one of them deals with the concept of work as a mission; the role becomes a goal and not an obligation, it becomes the meaning that will lead to pleasure and togetherness happiness. According to this approach, a person who chooses a role in which he/she can express his/her strengths will be happier and satisfied.

In summary, the role of integration aides has been examined from the perspective of the integrative aides, focusing on the challenges alongside the personal strengths that help dealing with them. Many of the challenges that the aide faces in her work are related to the complex nature of the integration work and the dilemmas that accompany this process, the nature of the school's teamwork, different attitudes regarding integration, the need for constant learning and training, etc. There is another challenge related to the low employment conditions of this role. Despite many challenges, it seems that performing this role provides a feeling of satisfaction, opportunities for growth and personal and professional development. As was phrased by A:

"There is an opportunity in the process, both for me and the student, to go through a challenging process in terms of placing a mirror, reflecting challenging social interactions. I'm facing the other, I'm facing the majority. There is an opportunity to improve skills that require improvement in a normative society. Decoding situations, interpersonal boundaries. Understanding what a connection is, dialogue. It's mostly timely opportunities for a lot of struggles and the ability to focus on the problem, analysing it."

The unique contribution of aides' role to the integration process has not been 
studied widely in the professional literature. For further research I would recommend on conducting combined qualitative and quantitative research examining the effect of personal and professional characteristics such as age, gender, seniority, and special education training on the aides' role as a highly significant component of the integration process. It is recommended to conduct wider research using the qualitative method that will deepen and broaden the understanding of the challenges and forces that accompany the role of integration aides.

\section{Conflicts of Interest}

The author declares no conflicts of interest.

\section{References}

[1] Law, K. and McPartland, J. (2016) Autism Spectrum Disorder. Yale Child Study Center, New Haven. https://doi.org/10.1016/B978-0-12-397045-9.00230-5

[2] Al-Qasheh, B. (2017) Autism-A Development in Understanding Disability on the Developmental Continuum. Lexi-Kay, 7, 3-4. (In Hebrew)

[3] Hiraiwa, M. (2012) High-Functioning Autistic Children. From a Physician's Perspective. $J M A J, 55,45-55$.

[4] Levinger, S. (2010) Care for Children with Communication Problems in Primary School Age. Publishing House, Krayat Bialik. (In Hebrew)

[5] Bauminger, N., Lake-Ben-Artzi, C., and Kimchi, Y. (2007) Educational and Social Integration of Children with High-Functioning Autism. In: Integrations: Studying with Disabilities in Educational Systems, Achah, Haifa, 461-497. (In Hebrew)

[6] Milstein, A. and Rivkin, D. (2013) Integrating Children with Special Needs in Regular Schools: Promoting Integration and Creating Integrative School Culture. MyersJoint-Brookdale Institute, Jerusalem. (In Hebrew)

[7] Neon, D., Milstein, A. and Marom, M. (2011) Integration of Children with Special Needs in Elementary Schools: Monitoring the Implementation of the "Integration Chapter" in the Special Education Law. Myers-Joint, Brookdale Institute, Jerusalem. (In Hebrew)

[8] Giangreco, M.F., Halvorsen, A., Doyle, M.B. and Broer, S.M. (2004) Alternatives to Overreliance on Paraprofessionals in Inclusive Schools. Journal of Special Education Leadership, 17, 82-90.

[9] Simpson, R., Boer-Ott, S. and Smith-Myles, B. (2003) Inclusion of Learners with Autism Spectrum Disorders in General Education Settings. Top Lang Disorders, 23, 116-133. https://doi.org/10.1097/00011363-200304000-00005

[10] Xen, L. and Kramer-Nevo, M. (2010) Data Analysis in Qualitative Research. BenGurion University: Book Publishing House, Beersheba. (In Hebrew)

[11] Shakedy, A. (2003) Words That Try to Touch: Quality Research-Theory and Application. Ramot Press, Tel Aviv University, Tel Aviv. (In Hebrew)

[12] Abramson, R., Golub, N., Kassirer, E., Irad, L. and Berger, A. (2017) Classes for Students on the Autistic Continuum in the Regular Education System, Rationale, Principles, and Action Plan. Ministry of Education, Pedagogical Administration, Division A, Special Education, Publications Division.

[13] Giangreco, M.F. (2013) Teacher Assistant Supports in Inclusive Schools: Research, 
Practices, and Alternatives. Australasian Journal of Special Education, 37, 93-106. https://doi.org/10.1017/jse.2013.1

[14] Seligman, M. (2005) True Happiness, Self-Realization through Positive Psychology. Modan, Ben Shemen. (In Hebrew)

[15] Ben-Shahar, T. (2010) In Happiness. Matar, Tel Aviv. (In Hebrew) 